\title{
Role of the Tumor Necrosis Factor Receptor 2 (TNFR2) in Cerebral Malaria in Mice
}

\author{
Pierre François Piguet, Chen Da Kan, and Christian Vesin \\ Department of Pathology, Universite de Geneve, Geneva, Switzerland
}

\begin{abstract}
SUMMARY: Infection of susceptible mice with Plasmodium berghei Anka leads to a syndrome of severe or cerebral malaria. Tumor necrosis factor (TNF) contributes to this syndrome, apparently by acting on its receptor 2 (TNFR2) because TNFR1-/- are susceptible, whereas TNFR2-/- mice are resistant. In this work, we confirmed the essential role of the TNFR2 in cerebral malaria because 6 to 8 days after Plasmodium berghei Anka infection, hypothermia, coma, and death were observed in +/+ or TNFR1-/-, but never in TNFR2-/-, mice. TNF production, evaluated by the serum levels or the mRNA levels in the brain, spleen or lung, was similar in +/+, TNFR1-/-, or TNFR2-/- mice. Macrophage or parasitized red blood cell sequestration in brain or lung was similar in TNFR1-/- and TNFR2-/- mice. Accordingly, up-regulation of CD54 or CD40 in brain or lung was also similar in TNFR1-/- or TNFR2-/- mice. Platelet loss, manifested by thrombocytopenia and the presence of microparticles in plasma, was similar in TNFR1-/- or TNFR2-/- mice. Breakdown of the blood-brain barrier, detected by the diffusion of tracers, was attenuated in both TNFR1-/- and TNFR2-/-, compared with +/+, mice. Endothelial cells from brain capillaries, examined by transmission electron microscopy, were similar in infected TNFR1-/- or TNFR2-/- mice, whereas the basement membrane was enlarged in TNFR1-/mice. Hypothermic mice were also hyperglycemic, and this was evident in $+/+$ and TNFR1-/-, but not in TNFR2-/-, mice. In addition, infected $+/+$ and TNFR1-/- mice became insulin resistant, while in contrast TNFR2-/- became extremely insulin sensitive. This study supports the possibility that coma and death are mediated not by cell sequestration or breakdown of vascular permeability, similar in TNFR1-/- or TNFR2-/- mice, but by metabolic disturbances selectively mediated by the TNFR2.
\end{abstract} (Lab Invest 2002, 82:1155-1166).

$I$ nfection with Plasmodium falciparum can lead to severe malaria, a heterogeneous syndrome involving respiratory and neurological disturbances with an important mortality (Marsh et al, 1996). Infection of some mouse strains by Plasmodium berghei ANKA $(\mathrm{PbA})$ results in a lethal syndrome, commonly named cerebral malaria (CM), in which mice die 7 to 9 days after infection in a state of coma (Wright, 1968). Coma occurs in mice with a parasitemia greater than $5 \%$. In nonsusceptible mouse strains, such as Balb/c, coma does not occur, and mice eventually die of complications of anemia after an infection of 3 to 4 weeks duration. Pathogenesis of the coma in either mice or humans is incompletely understood and has been attributed to different mechanisms, as reviewed in (Clark et al, 1997; White and Ho, 1992). Because CM is associated with sequestration of macrophages, parasitized red blood cells (pRBC), and platelets in the microvessels of the brain (Clark et al, 1992; Favre et al, 1999), this supports the possibility that the coma is due to cerebral hypoperfusion and hypoxia. Coma has also been attributed to a breakdown of the bloodbrain barrier, leading to cerebral edema, whose rela-

\section{DOI: 10.1097/01.LAB.0000028822.94883.8A}

Received February 28, 2002.

This study was supported by a grant no. 31-56839.99 from the Swiss National Science Foundation.

Address reprint requests to: Dr. Pierre F. Piguet, Universite de Geneve, Department of Pathology, 1 rue M. Servet, CMU, 1211 Geneva, Switzerland.E-mail:pierre.piguet@medecine.unige.ch tion with cell sequestration, if any, is not established (Newton et al, 1994). More recently, it has been argued that the coma is due to metabolic perturbations such as hyperlactatemia and alterations of glycemia. Because glycemia is the result of a balance between glucose production and use by the tissue, it is interesting that both have been reported to be modified by malaria infection in human or rodents (Clark et al, 1997; Holloway et al, 1991; Van Thien et al, 2001). One argument in favor of the metabolic hypothesis is that the coma is sometimes reversible, while this is less likely after an ischemia or a cerebral edema.

Various studies using antibodies, recombinant cytokines, or knock-out mice have shown that the secretion of tumor necrosis factor (TNF or TNF- $\alpha$ ) is an important effector of CM (Grau et al, 1987; Grau et al, 1989; Rudin et al, 1997). However, a recent investigation of the respective role of TNF- $\alpha$ and lymphotoxin (LT) $-\alpha$, using genetically deficient mice, suggests that the coma is mediated by the LT- $\alpha$ (Engwerda et al, 2002). Evidence for a major role of TNF in human CM is also compelling and includes the presence of TNF in plasma (Kwiatkowski et al, 1990) and the higher incidence of $\mathrm{CM}$ in subjects with high TNF-producing genotypes (Kwiatkowski, 2000). TNF or LT- $\alpha$ are ligated by two receptors (TNFR1 and TNFR2), and it has been reported that mortality and coma occur in TNFR1-/- but not in TNFR2-/- mice (Lucas et al, 1997a), indicating that the TNFR2 is playing a critical role in the expression of $\mathrm{CM}$.

TNF might be responsible for several of the manifestations of $\mathrm{CM}$, such as increase of the vascular 
permeability (Abe et al, 1990), perturbation of the glucose metabolism at several levels (ie glucose transport, hepatic gluconeogenesis and glycolysis) reviewed in previous reports (Clark et al, 1997; Evans et al, 1989), and sequestration of cells in the microcirculation. In this latter case, TNF might act by increasing the expression of the adhesion molecules CD54 (ICAM-1) and CD106 (VCAM) or CD40 on endothelia (Imhof and Dunon, 1995; Lucas et al, 1997b), that which might contribute to increasing the adhesion of leukocytes, pRBC, or platelets, and thereby disturb the microcirculation. This pathogenic hypothesis is supported by the increased expression of CD54 and CD106 in the brain microcirculation during CM and the delayed mortality seen in mice treated with anti CD11a monoclonal antibody (LFA-1, a $\beta 2$ integrin determinant) (Grau et al, 1991) or in CD54 deficient mice (Favre et al, 1999).

In the present work, we confirmed the absolute requirement of the TNFR2 for the expression of CM in $\mathrm{PbA}$ infected mice, but we did not confirm a specific role of the TNFR2 in the expression of CD54, suggested by Lucas et al (Lucas et al, 1997a), as well as in the cell sequestration in brain venules because these were similar in TNFR1-/- and TNFR2-/- mice. TNFR1 or TNFR2 deficiency did not decrease either TNF or CD4OL production, two important mediators of the expression of CM (Grau et al, 1987; Piguet et al, 2001a). Breakdown of the blood-brain barrier associated with infection was similar in TNFR1-/- or TNFR2-/- mice. In contrast, the perturbation of the glycemia seen in infected mice was selectively dependent upon the TNFR2. This study therefore supports the possibility that the coma and death of $\mathrm{CM}$ are mainly due to metabolic disturbānces, sēlectively mediated by the TNFR2, rather than by changes in vascular permeability or cell sequestration.

\section{Results}

Critical Role of the TNFR2 in the Mortality of PbA Infected Mice

In several experiments, we confirmed the original report of Lucas et al (Lucas et al, 1997a) concerning the critical role of the TNFR2 in the mortality of PbA infection. In our experiments, the majority of the TNFR1-/- mice died in a state of coma 6 to 8 days after infection at the same time or slightly before the $+/+$ controls, while none of the TNFR2-/- (a total of 54 were examined in different experiments) became sick or died during the acute phase of the infection. In accord to what has been reported before, the percentage of pRBC was similar and of the order of $5 \%$ after an infection with $5 \times 10^{4} \mathrm{pRBC}$ in $+/+$, TNFR1-/-, and TNFR2-/- mice (not shown).

On the seventh day after infection, mice exhibit deregulation of thermoregulation; they are briefly hyperthermic, and subsequently they become hypothermic when they fall into coma, as described before (Curfs et al, 1989). Mice with a temperature below $32^{\circ} \mathrm{C}$ are immobile and comatose. Little change in temperature occurred in TNFR2-/- mice, while in both +/+ or TNFR1-/- mice hypothermia was evident (Fig. $1 \mathrm{~A})$.

\section{Role of the TNF-R1 and TNF-R2 in the Breakdown of the Vascular Impermeability}

Groups of infected mice were injected with Evans blue on Day 7 after infection to evaluate vascular permeability. Leak of Evans blue was markedly increased in the brain and other organs of infected $+/+$ mice compared with noninfected controls. Leak was attenuated in both TNFR1-/- and TNFR2-/- mice (Fig. 2A).

Vascular permeability was also explored by the injection of $\mathrm{I}^{125}$-albumine. Localization of albumin in brain was increased about 3-fold in infected $+/+$, and this was similar in both TNFR1-/- or TNFR2-/- mice (Fig. 2B).

An increase of the vascular leak, evidenced by Evans blue, was also evident in other organs such as the lung. In the lung, in contrast to the brain, the leak results in a significant increase of the lung weight, which is therefore another evaluation of the vascular leak. Lung weight was significantly higher in $\mathrm{PbA}$ infected $+/+$ mice than in noninfected mice, and increase of lung weight was also evident in both TNFR1-/- and TNFR2-/- infected mice (Fig. 2C).

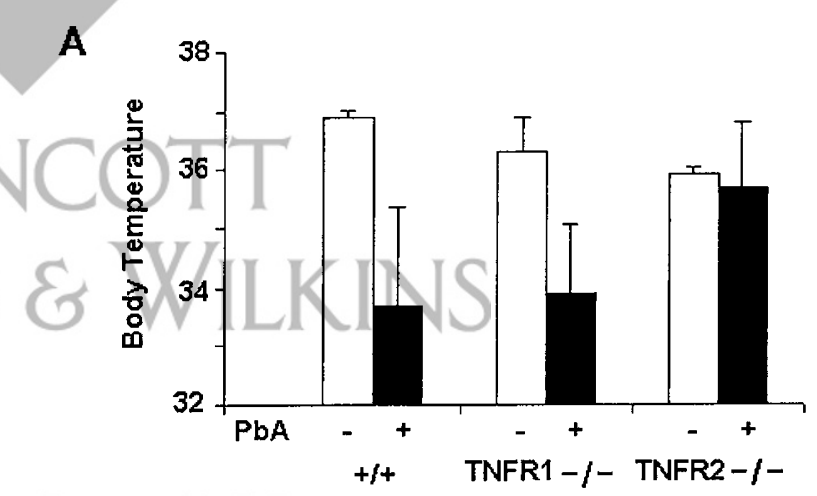


A

B6 $+1+$

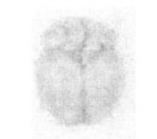

B6+1+

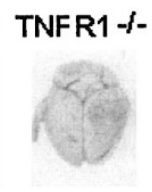

TNF R2-1-

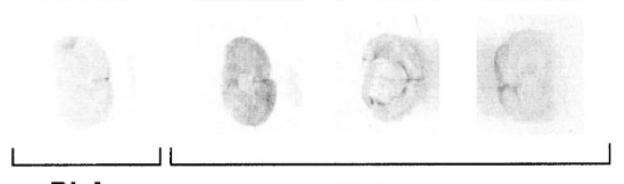

PbA -

$\mathrm{PbA}+$

B

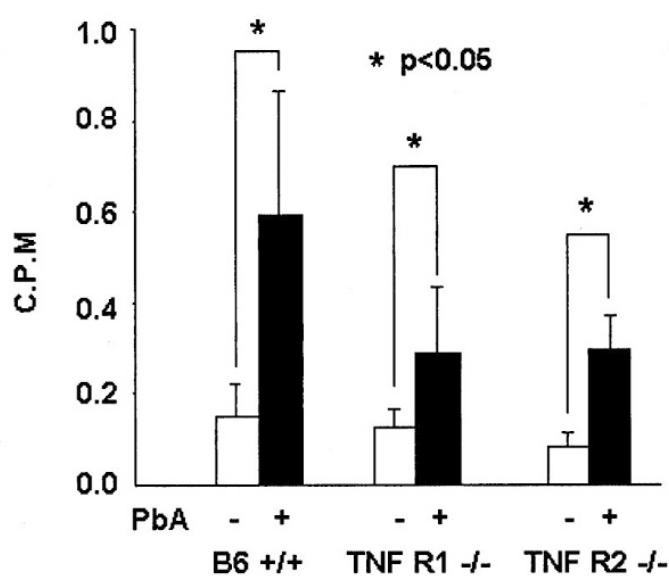

C

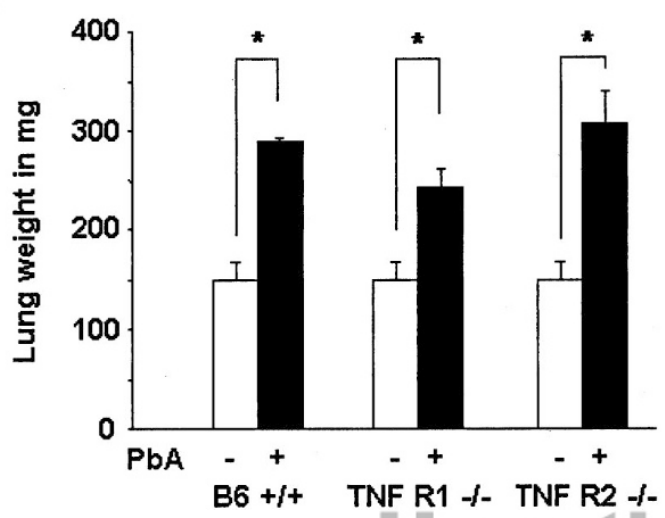

Figure 2.

Evaluation of vascular leak. Groups of mice were examined 7 to 8 days after $\mathrm{PbA}$ infection. Top: mice were injected with Evans blue and killed after 2 hours. Leakage of blue is evident in brain of infected $+/+$, compared with noninfected mice, and to a lesser extent in TNFR1-/-, or TNFR2-/- mice. Middle: diffusion of $\mathrm{I}^{125}$ albumin. Mice were injected with $\mathrm{I}^{125}$ labeled albumin and killed after 3 hours. Results are the mean $(\mathrm{SD}, n=6)$ of the ratio of counts per minute in brain and in $0.1 \mathrm{ml}$ of blood seen in individual mice. Bottom: mean $(\mathrm{SD}, n=6)$ of the lung weight. The lung weight is significantly $(p<0.05)$ increased in infected, compared to noninfected controls, in +/+, TNFR1-/-, or TNFR2 -/- mice.

These observations indicate that the increase of vascular leak in the brain and lung can be induced by either the TNFR1 or TNFR2 alone. In addition, because the vascular leak was attenuated but similar in both TNFR1-/- or TNFR2-/- mice, this argues that the vascular leak is not sufficient to elicit the coma seen in infected TNFR1-/- mice.

\section{Role of the TNFR1 and TNFR2 in the Thrombocytopenia}

Seven days after $\mathrm{PbA}$ infection, platelet counts are below $500 \times 10^{3} / \mathrm{mm}^{3}$, and this is due in great part to a reduced platelet life span (Grau et al, 1988). Thrombocytopenia was severe in both infected TNFR1-/and TNFR2-/- mice (Table 1).

We also examined platelet lifespan in these mice, using the in vivo biotinylation method (Ault and Knowles, 1995). Platelet half life was 30 hours in the noninfected $+/+$ mice and reduced in similar proportion in infected +/+, TNFR1-/-, and TNFR2-/- mice to about 24 hours. However, platelet lifespan was also reduced in noninfected TNFR1-/- and TNFR2-/- mice, suggesting a defect in these mice independent of the infection (not shown).

$\mathrm{PbA}$ infection is also associated with a marked increase of the proportion of microparticles ( $\mathrm{mcp}$ ) in plasma, suggesting that platelets break up in circulation (Piguet et al, 2002). In TNFR1-/- or TNFR2 -/mice, the presence of mcp was already significantly increased in noninfected mice and not significantly increased by infection (Fig. 3).

In $+/+$ mice, the platelet loss induced by the infection was to some extent compensated by a marked increase of megakaryocytopoiesis, evident in the spleen red pulp by an increase of the number of megakaryocytes (mk) per unit area. An increase of megakaryocytopoiesis has also been reported in lungs of $\mathrm{PbA}$ infected mice (Carvalho et al, 2000). In noninfected TNFR1-/- and TNFR2-/- mice, an increase of the number of $\mathrm{mk}$ was already evident, while these mice did not further increase the number of $\mathrm{mk}$ in response to $\mathrm{PbA}$ infection (Table 1).

Thus, the TNFR1-/- and TNFR2 -/- mice have less stable platelets than the $+/+$ mice, which is compensated for by an increased platelet production. Taking into account these control values, $\mathrm{PbA}$ infection did not further markédly reduce platelet lifespan in TNFR $1-/$ - or TNFR2-/- deficient mice and also did not increase platelet production. The absence of a substantial difference in platelet kinetics between infected TNFR1-/- or TNFR2-/- mice does not provide an explanation for the difference in clinical course.

Role of the TNF1-/- and TNFR2-/- in the Sequestration of Macrophages and $p R B C$

In the brain, examined by conventional histology, leukocyte sequestration is evident in venules (Grau et al, 1987). Leukocyte sequestration was evaluated on brain sections of infected TNFR1-/-, TNFR2-/-, or +/+ mice. Leukocyte sequestration was similar in TNFR1-/- and TNFR2-/- mice and slightly less severe than in $+/+$ mice (Fig. 4).

During CM, the cellularity of the alveolar septa is increased due to a sequestration of macrophages, polymorphonuclear leukocyte (PMN), pRBC, and platelets in the alveolar capillaries (Coquelin et al, 1999; Piguet et al, 2001a). Sequestration was evaluated by semiquantitative electron microscopy, as described before (Piguet et al, 2001a). The number of macrophages in the alveolar capillaries was similarly decreased in TNFR1-/- or TNFR2 -/- mice compared with $+/+$ mice (not shown). In the alveolar capillaries, the percent of pRBCs is significantly higher than in the 
Table 1. Mortality, Thrombocytopenia, and Megakaryocytopoiesis in Different Mouse Strains

\begin{tabular}{|c|c|c|c|c|c|}
\hline \multirow[b]{2}{*}{ Strains } & \multirow[b]{2}{*}{ Infection } & \multirow[b]{2}{*}{ Mortality } & \multirow[b]{2}{*}{ Platelets $\left(\times 10^{3} / \mu \mathrm{l}\right)$} & \multicolumn{2}{|c|}{ Spleen } \\
\hline & & & & $(\mathrm{mg})$ & $\mathrm{MK} / \mathrm{mf}^{a}$ \\
\hline $\mathrm{C} 57 \mathrm{BI} / 6$ & - & - & 1176 (258) & $84(13)$ & $0.36(0.2)$ \\
\hline C57BI/6 & + & yes & 389 (102) & $284(67)$ & $1.20(0.4)$ \\
\hline \multirow[t]{2}{*}{ TNFR2 -/-, } & - & - & $716(75)^{\prime}$ & 120 (14) & $2.6(1.3)$ \\
\hline & + & no & $431(75)$ & 304 (45) & $1.3(0.7)$ \\
\hline \multirow[t]{2}{*}{ TNFR1 -/- } & - & - & 1047 (59) & $151(14)$ & $1.7(0.9)$ \\
\hline & + & yes & 559 (108) & $226(43)$ & $0.3(0.2)$ \\
\hline
\end{tabular}

Results are the mean (SD) of the values observed in different experiments on a total of greater than 6 mice. Mortality was scored 7 to 8 days after infection, and blood measurements were also performed on days 7 to 8 after infection.

${ }^{a}$ Number of megakaryocytes/microscopic field of the spleen red pulp.

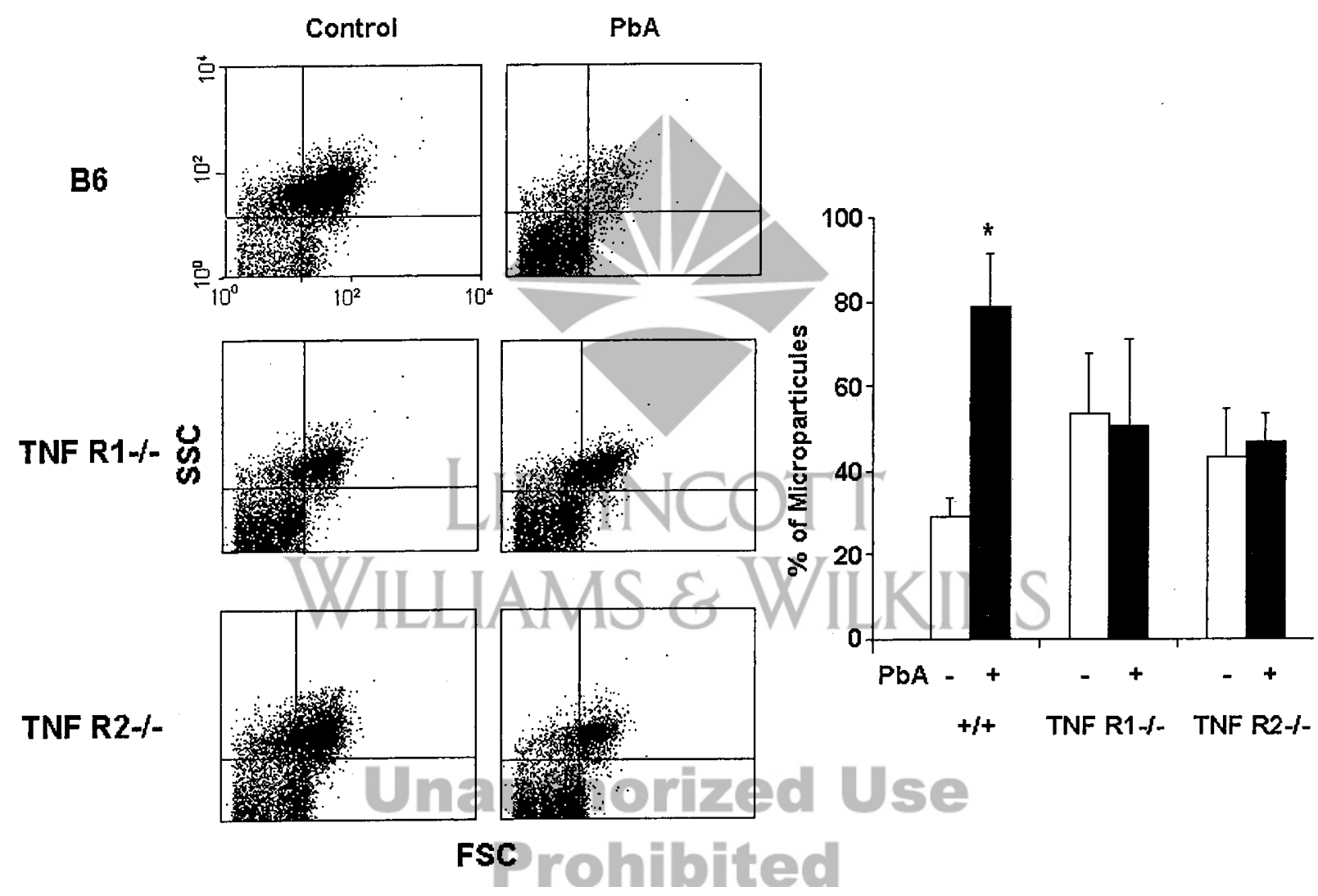

Figure 3.

Microparticles in plasma from TNFR1-/- and TNFR2-/- mice. Left: representative example of the distribution of events in the platelet rich plasma from individual mice. The events in the upper right quadrant correspond to platelet, while those in the lower left correspond to microparticles. Right: the mean (sD, $n=5$ ) of the percent of events in the lower left quadrant. The incidence of microparticles is increased $(p<0.05)$ in infected $+/+$ compared with noninfected. In noninfected TNFR1-/or TNFR2-/-, the percent of microparticles is significantly higher than in $+/+$ mice, whereas there is no significant difference between infected or noninfected TNFR1-/or TNFR2-/- mice.

main blood vessels, indicating that pRBC are selectively adherent in the alveolar capillaries (Coquelin et al, 1999; Favre et al, 1999). Parasitemia, determined by transmission electron microscopy in major lung blood vessels and alveolar capillaries, was 5 (1) and 11 (2) for +/+ mice, 4 (2) and 10 (2) for TNFR1 -/- mice, and 5 (1) and 12 (3) for TNFR2-/- mice, respectively (mean and SD, $n=5$ ).

Thus, neither the TNFR1 nor the TNFR2 played a selective or specific role in the sequestration of mac- rophages or $\mathrm{pRBC}$ in either brain venules or alveolar capillaries.

\section{Alteration in the Brain Blood Vessels}

The most severe vascular lesion is a microhemorrhage, detectable macroscopically, and which, on histological sections, is localized around venules (Senaldi et al, 1994). Microhemorrhages occurred in infected CBA/J (Senaldi et al, 1994), but were not 

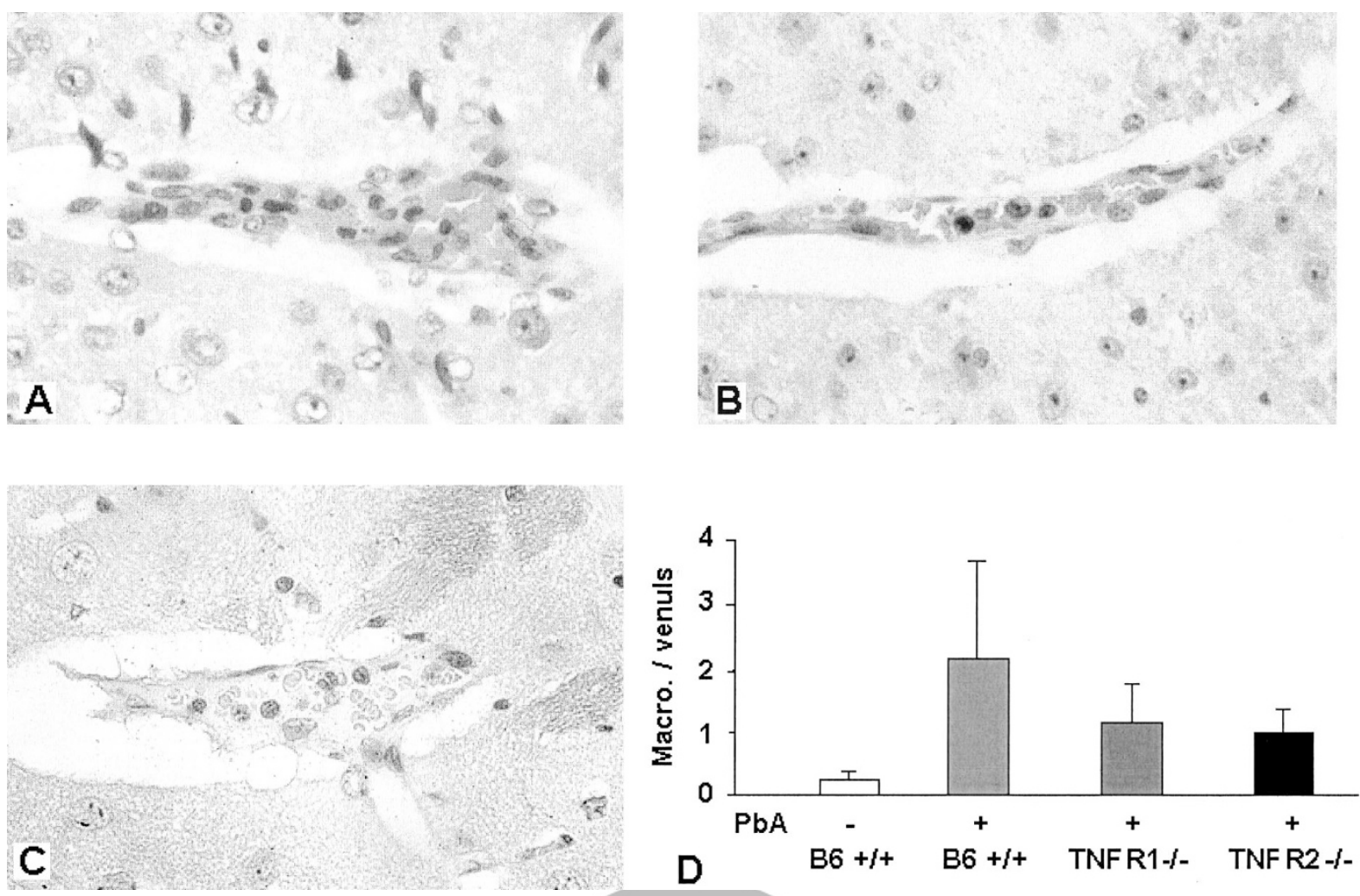

Figure 4.

Leukocyte sequestration in cerebral venules. A to $\mathrm{C}$, representative examples of venular sequestration in individual $+/+(A)$, TNFR1-/- (B), and TNFR2-/-/C) infected mice. Cortical venules contain numerous leukocytes. Original magnification $\times 400$. D, the mean $(\mathrm{SD}, n=5)$ of the leukocyte/endothelial cell ratios seen in cortical venules from five individual mice. The leukocyte/endothelial cell ratio is significantly $(p<0.05)$ increased in all infected mice, compared with noninfected $+/+$ mice.

observed in mice on the C57BI/6 background. This is probably related to the more abundant leukocyte sequestration seen in CBA/J than in the C57BL/6 (not shown). This also suggests that microhemorrhages contribute to the localized neurological symptoms occasionally observed in CBA/J but not in the coma seen in both CBA/J or C57BI/6.

In cerebral venules, leukocyte sequestration can be associated with endothelium cell death, which can be observed by transmission electron microscopy and which has already been documented (Chang-Ling et al, 1992; Grau et al, 1993). Five venules from infected TNFR1-/- were examined by transmission electron microscopy, and none of these exhibited significant endothelial damage (not shown).

We also performed an evaluation of the cortical capillaries by semiquantitative transmission electron microscopy. Cytopathic alterations of endothelial cells were rare in both TNFR1-/- or TNFR2-/- mice and interendothelial junctions were always intact (Fig. 5). A semiquantitative evaluation of the capillary endothelium volume and surface also did not demonstrate a significant difference between TNFR1-/- and TNFR2-/- mice (Table 2). Semiquantitative evaluation of the endothelial vesicles performed as described (Stewart et al, 1994) did not demonstrate either a significant difference between TNFR1-/- and TNFR2-/- mice (not shown). The only significant difference observed concerned the perivascular space (including the basement membrane), which was sig- nificantly larger in TNFR1-/- than in TNFR2-/- mice (Table 2 ; Fig. 5).

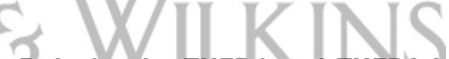 \\ Role for the TNFR1 and TNFR2 in the Expression of CD54, CD40, TNF, and CD40L mRNAs}

Former studies have demonstrated the requirement of CD40 and CD54 for the expression of CM (and the vascular leak), molecules which are expressed on the endothelium. We therefore explored the expression of these molecules by both histochemistry and by the evaluation of their mRNAs on Northern blots:

1. CD54: expression of CD54 is increased in cerebral vessels of $\mathrm{PbA}$ infected mice, in both capillaries and venules, as documented before (Grau et al, 1991). In the present experiments, we observed a similar increase of the expression CD54 in small blood vessels of infected TNFR1-/- and TNFR2-/- mice (not shown).

Expression of CD54 mRNA is also increased in the brains of $\mathrm{PbA}$ infected mice, and its amount can be evaluated by objective methods. Induction of CD54 mRNA was evident in both infected TNFR1-/- and TNFR2-/- mice, without significant difference between them (Fig. 6).

2. CD40: CD40 is weakly detectable in the venular endothelium by histochemical methods, and no significant difference was observed between TNFR1-/- or TNFR2-/- (not shown). The CD40 mRNA was significantly increased in infected $+/+$ mice, compared with 

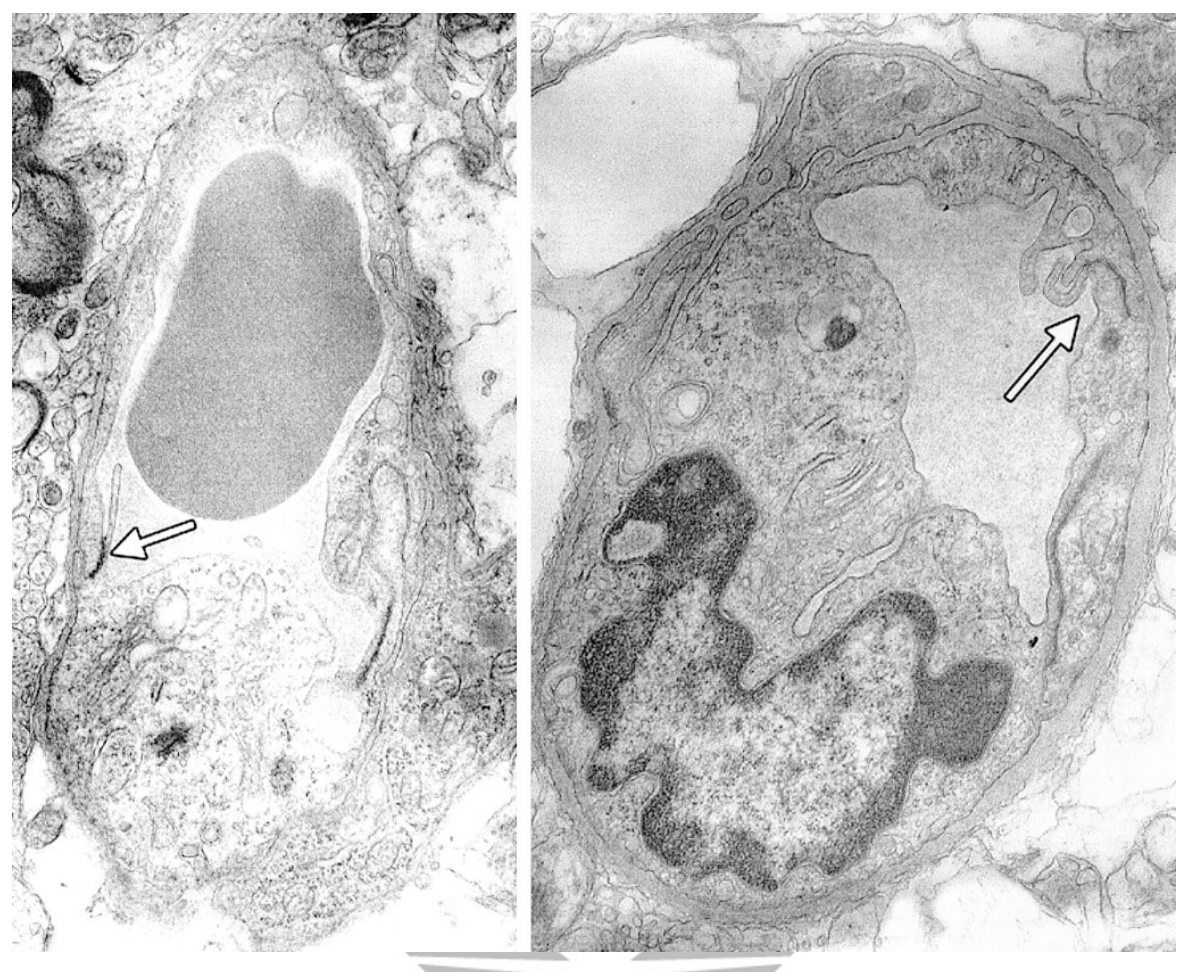

Figure 5.

Cerebral capillaries from infected mice seen by transmission electron microscopy. Capillaries from the cortex of TNFR2-/- (left) or TNFR1-/-(right) infected mice. The junctions (arrow) are intact. The endothelial cells do not exhibit substantial cytopathic alterations. The basement membrane from the TNFR1-/- is enlarged compared with that of the TNFR2-/- mice.

Table 2. Brain Capillaries in PBA Infected Mice

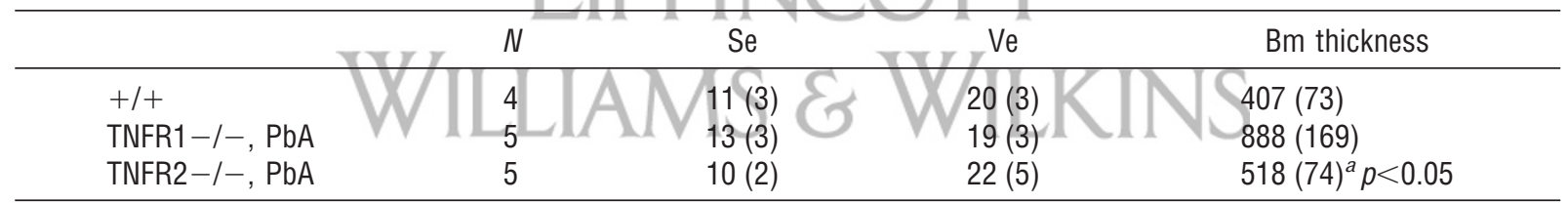

Se, endothelial surface; Ve, endothelial volume in arbitrary units; Bm, basement membrane.

Bm thickness is in $\mathrm{nm}$.

${ }^{a}$ Results are the mean (SD) of the values observed in individual mice.

\section{Unathorized Use}

the noninfected controls, and a similar increase was also evident in TNFR1-/- or TNFR2-/- mice (Fig. 6).

3. TNF: In plasma, the TNF levels were of greater than 1 in noninfected mice, and 62 (25), 73 (26), and 68 (16) $\mathrm{pg} / \mathrm{ml}$ for $+/+$, TNFR1-/-, and TNFR2-/- mice, respectively (mean and SD, $n=5$ ). TNF mRNA levels were increased in the lung, spleen, and brain of $\mathrm{PbA}$ infected mice, and this was similar in $+/+$, TNFR1, or TNFR2-/- mice (Fig. 6). These results indicate that $\mathrm{PbA}$ infection induces a similar increase of TNF production in +/+, TNFR1-/-, and TNFR2-/- mice.

4. CD40L: CD4OLmRNA is not markedly modified by $\mathrm{PbA}$ infection in the lung, brain, and spleen. It is increased in the spleen if the splenomegaly is taken into account (Piguet et al, 2001a). No substantial modification of CD40L mRNA was detected in TNFR1-/- or TNFR2-/- mice, which could suggest that the TNFRs exert some specific role in the expression of the CD40L.

\section{Glycemia and Response to Insulin}

Mice infected with $\mathrm{PbA}$ have been reported to be hyperglycemic (Clark and Bowden, 1992). Glycemia was higher in infected $+/+$ and TNFR1-/- mice, while glycemia was not modified by infection in TNFR2-/mice (Fig. 1). Coma occurred only in $+/+$ or in TNFR1-/- mice, and comatose mice had a glycemia greater than $10 \mathrm{mmol} / \mathrm{L}$.

We also explored the response to insulin in untreated or infected $+/+$ and TNFR deficient mice. In noninfected mice, the response to insulin was similar in +/+ or TNFR1-/- mice, whereas TNFR2-/- mice were slightly more insulin resistant (Fig. 7).

$\mathrm{PbA}$ infection is known to be associated with a low insulin level (Elased et al, 1996). The response to insulin was similarly decreased in +/+ and TNFR1-/infected mice, whereas, in contrast, the TNFR2-/mice became extremely insulin sensitive and died of hypoglycemia during the test (Fig. 7). 

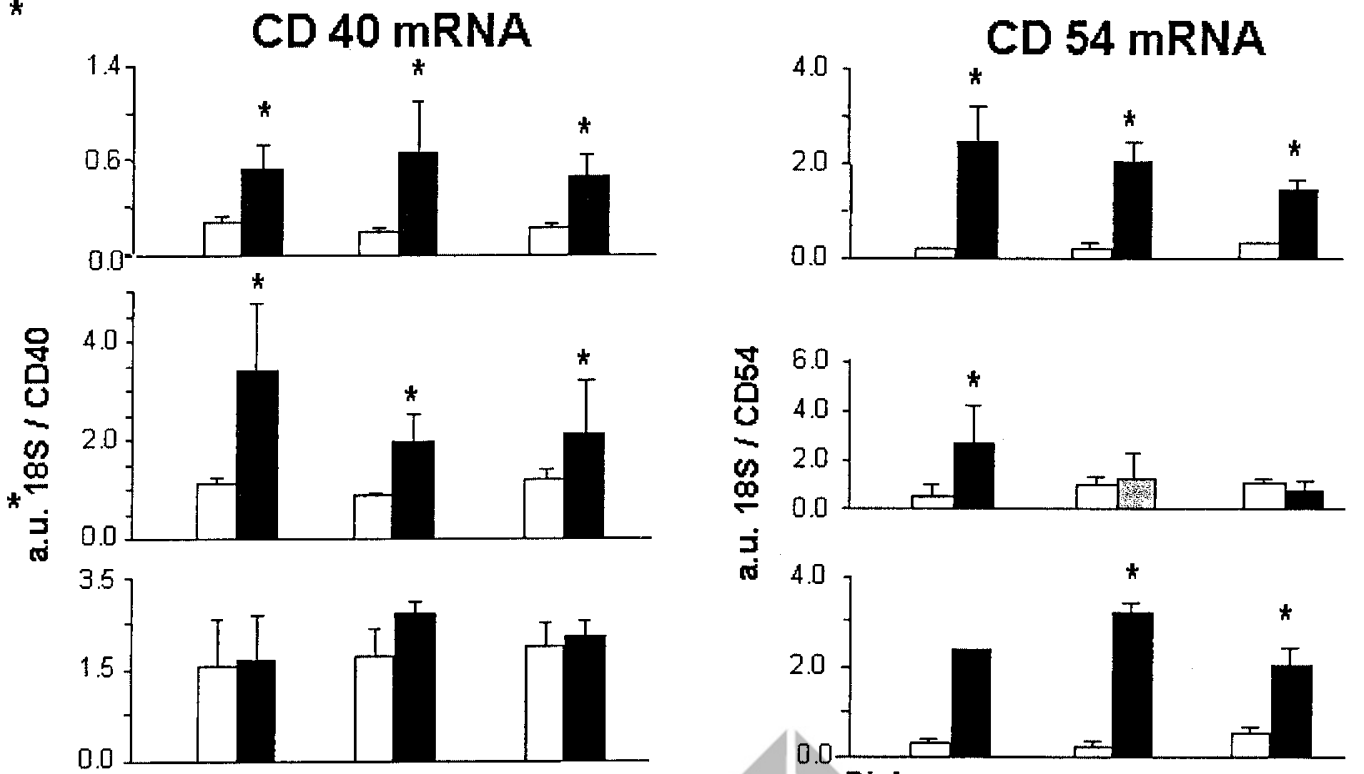

BRAIN

0.0
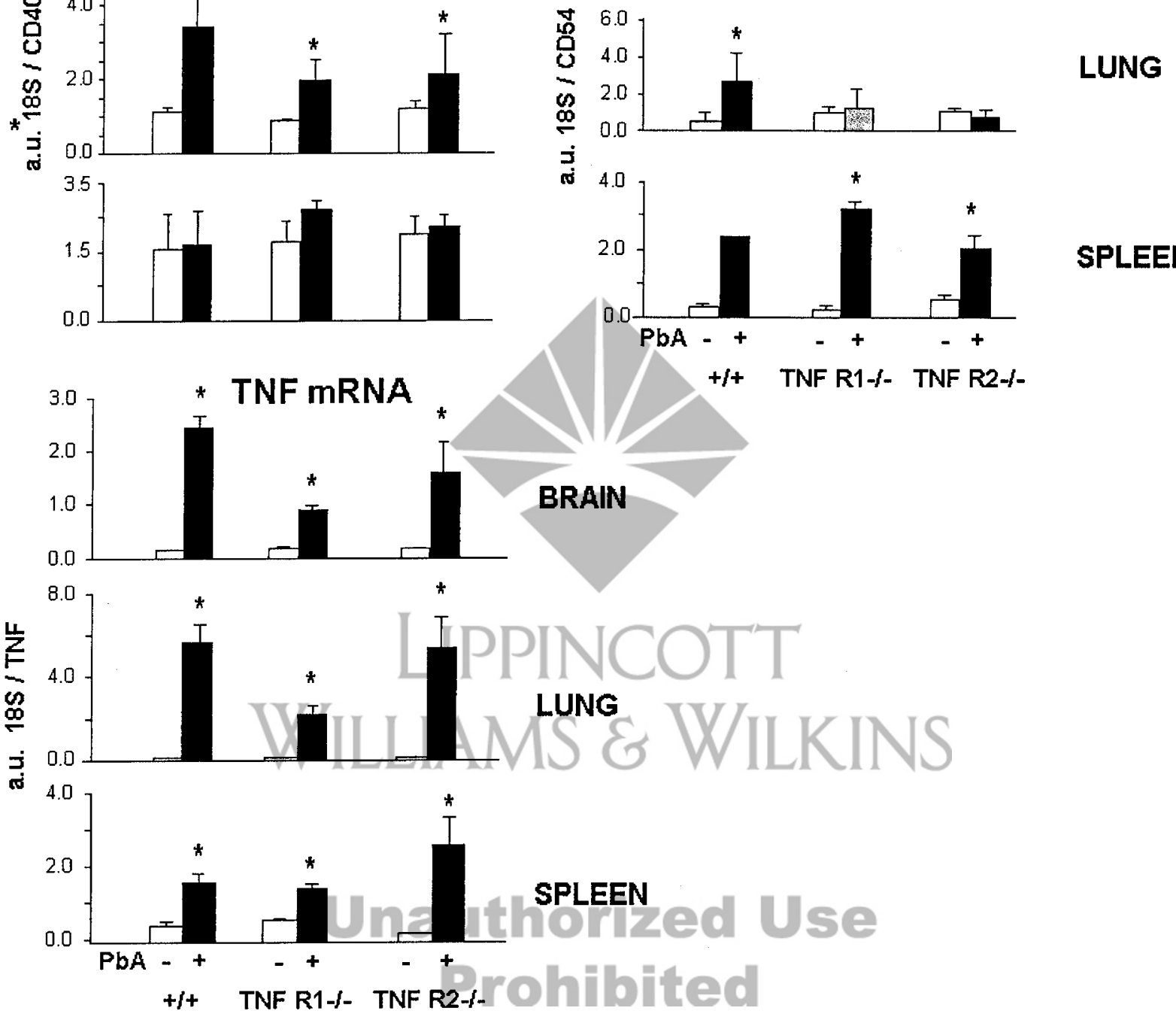

Figure 6.

Expression of CD40, CD54 (ICAM-1), and TNF mRNA. Results are the mean (sD, $n=5$ for infected and noninfected $+/+$ mice, and 2-3 for noninfected TNFR1 -/or TNFR2 -/- mice) of the quantification of the mRNAs, expressed in arbitrary units, as detected on Northern blots. *Values significantly different $(p<0.05)$ from the $+/+$ noninfected mice.

Thus, the TNFR2 is the critical effector of change in glycemia associated with the coma.

\section{Discussion}

TNF is known to play a key role in the expression of inflammatory and infectious diseases and in the majority of cases appears to act through the TNFR1 (Douni and Kollias, 1998; Uysal et al, 1998). CM is therefore a rare situation in which the expression of a disease is selectively mediated by the TNFR2.
$\mathrm{PbA}$ infection leads to an important increase of TNF production, suggested by an increase of the mRNA levels in the spleen, lung and brain and the presence of the protein in plasma. These responses were similar in infected TNFR1-/- or TNFR2-/- mice and can therefore not explain the difference in clinical course. One of the effects of TNF is to increase the expression of adhesion molecules, such as CD54, CD106, or CD40, on the endothelium and thereby the adhesion of cells which bear the $\beta 2$ integrin, which includes macrophages, PMN, platelets, and pRBC (Favre et al, 1999; 

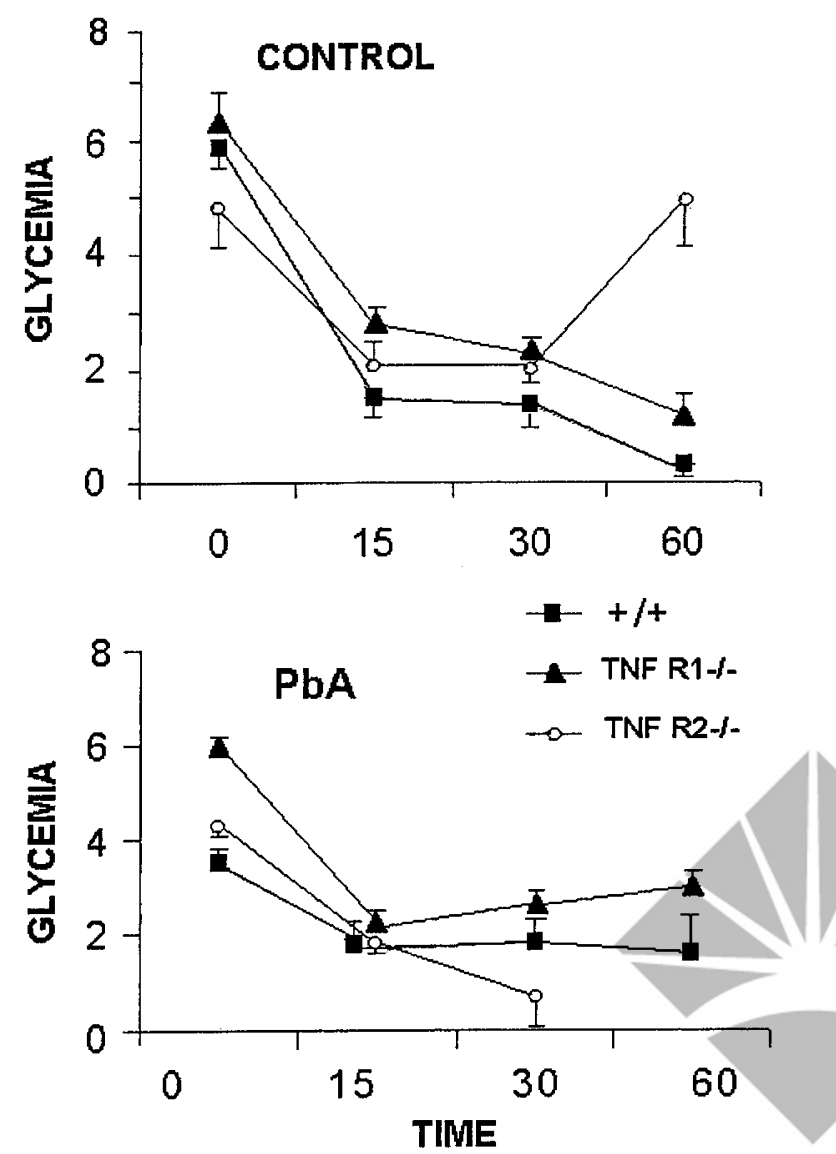

Figure 7.

Response to insulin in normal or $\mathrm{PbA}$ infected mice. Glycemia (in mmol/l) was measured after an injection of insulin in (5-6) noninfected (top) or infected (bottom) mice, examined 7 days after infection. Infected TNFR2-/- mice were all dead 30 minutes after insulin injection.

Piguet et al, 2001a). Expression of adhesion molecules is under the control of the transcription regulator NF-kB, which can be activated by signaling through either the TNFR1 or the TNFR2 (Baker and Reddy, 1998; Pober, 2002) Accordingly, we did not find a substantial difference in the expression of CD54 in TNFR1-/- or TNFR2-/- mice. Similar absence of correlation between the expression of CD54 and incidence of coma has also been recently observed (Engwerda et al, 2002). No significant difference in the expression of CD40 was observed either. Also, consistently, leukocyte sequestration in venules, or pRBC sequestration in alveolar capillaries, was similar in TNFR1-/- or TNFR2-/- mice. We therefore do not confirm the possibility, suggested by Lucas et al (Lucas et al, 1997a), that the TNFR2 plays a specific role in the induction of the cerebral CD54 and consequently in leukocyte sequestration in cerebral venules.

If $\mathrm{CM}$ is always associated with a severe thrombocytopenia, the role of the platelet loss in the expression of $\mathrm{CM}$ is not delimited. However, it might not be coincidental that two important mediators of CM, TNF and CD40L, reduce platelet lifespan (Piguet et al, 2001a; Tacchini-Cottier et al, 1998). In malaria infected subjects, platelets adhere to the activated endothelium (Piguet et al, 2000a) and might therefore contribute to endothelium activation. In addition, $\mathrm{PbA}$ infection is associated with a marked increase of platelet derived mcp in plasma (Piguet et al, 2002), which might deliver platelet products to various cells. Platelet loss is compensated by an increased megakaryocytopoiesis, a process which might result in an increase of the production and release of mediators in circulation, among which transforming growth factor- $\beta$ might be of importance, because this cytokine has been reported to attenuate the manifestations of CM (Omer and Riley, 1998). Platelet kinetics were already abnormal in both TNFR1-/- or TNFR2-/mice, and the impact of $\mathrm{PbA}$ infection is therefore difficult to evaluate; however, no substantial difference in platelet kinetics appeared between infected TNFR1-/- or TNFR2-/- mice, which might provide an explanation for the critical role of the TNFR2 in the coma.

The role of the breakdown of the blood-brain barrier in the manifestations of $\mathrm{CM}$ in humans is presently controversial, perhaps because of the heterogeneity of the disease, reviewed in White and Ho (1992). Cerebral edema has, however, been documented in the most severe cases of malaria (Newton et al, 1994). In PbA infected mice, the break down of the bloodbrain barrier is generally associated with the coma (Favre et al, 1999; Piguet et al, 2001a; Senaldi et al, 1994; Thumwood et al, 1988). However, coma occurred in TNFR1-/-, but not in TNFR2-/- mice, whereas the increase of vascular permeability in the brain (or lung) was moderate (compared with $+/+$ mice) and similar in these mice, suggesting that the increase of vascular permeability is not the main cause of the coma. There is evidence, from the study of retina whole mount, that the leak occurs first in venules, in association with leukocyte sequestration, and subsequently in capillaries (Chang-Ling et al, 1992). As already documented, leukocyte sequestration in venules might be associated with endothelial cell damage (apoptosis) and opening of the intercellular junctions (Chang-Ling et al, 1992). In capillaries, in contrast, no substantial alteration of endothelial cells, such as fenestration, as observed after vascular endothelium growth factor infusion (Feng et al, 1999), endothelial cell apoptosis or opening of the intercellular junctions, was observed. Surprisingly, the capillaries from TNFR1-/- mice did exhibit a significant thickening of their perivascular space, compared with those of TNFR2-/- mice. Similar enlargement of the basement membrane of venules has already been reported in $\mathrm{PbA}$ infected mice (Polder et al, 1992). Because this enlargement of basement membrane resembles that seen in diabetes (Cotran et al, 1994), it might be associated with hyperglycemia but not with an increase of vascular permeability.

Malaria infection or TNF injection can both induce complex modifications of glucose metabolism, resulting in hypo or hyperglycemia, as reviewed in earlier reports (Clark et al, 1997; Tracey et al, 1986). The glycemia is the result of a balance between glucose release in circulation and uptake by tissues, and, interestingly, TNF injection or malaria infection have 
both been reported to be associated with pleiotropic changes in glucose metabolism, such as an increase of hepatic gluconeogenesis, a decrease of glycogenolysis, and a decrease of glucose uptake (Uysal et al, 1998; Van Thien et al, 2001). Studies with cell lines indicate that TNF might increase the expression of the GLUT1 glucose transporter and inhibit insulin signaling in adipocyte and thereby influence glucose uptake, as reviewed in previous studies (Liu et al, 1998; Saltiel and Kahn, 2002). In spite of these pleiotropic regulations, it is surprising that glycemia was not modified in TNFR2-/- mice, indicating that TNF, acting on the TNFR2, is the essential mediator of the hyperglycemia seen in PbA infected mice. TNF is suspected to play a role in the regulation of the response to insulin, as suggested by the studies of cell lines (Liu et al, 1998; Sethi et al, 2000) and, in uninfected mice, we indeed observed an increased insulin resistance in TNFR2-/mice. Response to insulin is known to decrease in infected mice (Elased et al, 1996), and this was detected in both $+/+$ and TNFR1-/- mice, while in contrast, infected TNFR2-/- mice became extremely insulin sensitive. This demonstrates that the increase in insulin resistance observed during malaria infection is essentially mediated by TNF, acting on its TNFR2, whereas, in contrast, the TNFR1 selectively increases the response to insulin.

Pathogenesis of the coma associated with $\mathrm{PbA}$ infection is not well understood but is exclusively mediated by the TNFR2. Although the TNFR1 and TNFR2 appear to exert a similar contribution to the perturbations of the microcirculation, such as induction of adhesion molecules, cells sequestration, and vascular leak, the TNFR2, in contrast, has a selective role in the perturbation of the glycemia and the increased insulin resistance associated with the coma. These observations therefore support the possibility that the coma is mediated by metabolic perturbations under the control of the TNFR2.

\section{Materials and Methods}

\section{Mice}

TNFR1-/- (B6-Tnfr1*0) and TNFR2-/- (B6-Tnfr2*0) mice on the $\mathrm{C} 57 \mathrm{BI} / 6$ background were a gift from Horst Bluethman, (Hoffmann La Roche, Basel, Switzerland) and were bred in our animal facilities. C57BL/6J (B6) were used as wild type $(+/+)$ controls.

\section{Plasmodium berghei Anka Infection}

$\mathrm{PbA}$ has been passed in rodents (Wright, 1968), and mice were infected by an iv injection of $5 \times 10^{4} \mathrm{pRBC}$.

\section{Blood}

Blood $(0.015 \mathrm{ml})$ was isolated from the retro-orbital plexus of ethane anesthetized mice using heparinized capillaries and diluted in EDTA (1\% final), in accord with the Swiss national guidelines. Blood elements were counted in a cell counter (Casy 1, Schärfe system, D-72760, Reutlingen, Germany). Parasitemia was counted on blood smears stained with May Grunwald Giemsa. Glycemia was measured using the DEX glycometer (Bayer AG, B-1050, Leverkusen, Germany). Response to insulin was tested with an ip injection of insulin $(0.75 \mathrm{U} / \mathrm{kg}$, in mice fasting for 4 hours) and measuring the glucose level 15, 30, and 60 minutes later.

\section{Assessment of Vascular Permeability}

Mice (three wild types and three mutants) were injected intravenously with $0.2 \mathrm{ml}$ of $1 \%$ Evans blue on day 6 , shortly before death of the wild type mice. One hour later, mice were killed and the staining of brain sections was assessed as an indicator of increased capillary permeability.

\section{Platelet Lifespan}

Platelet kinetics were evaluated by the in vivo biotinylation method, and the percentage of labeled platelets was determined by fluorescence-activated cell sorter analysis (Ault and Knowles, 1995).

\section{Flow Cytometry}

Mcp and platelets were stained with a rabbit antimouse platelet antibody, purchased from Inter Cell Technologies Inc. (Hopewell, New Jersey). As a control, a nonimmune rabbit immunoglobulin fraction was used.

Mcp (ie, a supernatant from a platelet rich plasma centrifuged at $1500 \mathrm{~g}$ ) were fixed in $1 \%$ paraformaldehyde, washed by centrifugation at $9500 \mathrm{~g}$, incubated with anti-platelet or nonimmune rabbit immunoglobulin, which was subsequently detected by a fluorescein isothiocyanate (FITC)-labeled goat antirabbit antibody (Caltag Laboratories, L4 2001, Burlingame, California).

Suspensions were examined with a FACScan flow cytometer (Beckton Dickinson, Montain View, California). Mcp were identified by looking at side (SSC) and forward (FSC) angle light scatter in logarithmic acquisition mode. For immunofluorescence, analytic gates were set around platelets or mcp in logarithmic acquisition mode. Platelets were thus distinguished from larger or smaller elements such as red blood cells (or leukocytes) and mcp, respectively, as described before (Piguet et al, 2001b). In addition, fluorescent latex beads, (Sigma Chemical, St. Louis, Missouri; mean diameter $1.9 \mu$ ) were also used to define the size of the events observed.

\section{Light and Electron Microscopy}

Mice were killed by an ip injection of Nembutal, and the aorta was cut. The brain was isolated and immersion fixed in formaldehyde $5 \%$ in ethanol $70 \%$. Frontal sections were prepared for ordinary histology. Venules within the cortex were examined, and the endothelial cells and macrophages were counted. Endothelial cells were counted ( $>50 /$ sections), and the sequestration was evaluated by the macrophage/endothelial 
ratio. Megakaryocytopoiesis was evaluated on sections of the spleen by counting at a magnification of 400-fold, the number of $\mathrm{mk} / \mathrm{microscopic}$ field, as described previously (Piguet et al, 2000b).

To examine the lung, the thorax was opened, and the lung was fixed by intratracheal instillation of glutaraldehyde (5\% in $0.1 \mathrm{M}$ cacodylate buffer) and processed for epon embedding. A section was taken in the left lobe, across the hilus. Thin sections were prepared from two blocks/mice taken from the parenchyma. Thin sections were examined with a Philips 400 electron microscope at $60 \mathrm{kV}$. Cells within alveolar capillaries were examined, and red blood cells (RBC), pRBC, platelets, and PMN were counted. About 100 RBC were counted per individual thin section. RBC were used as a neutral indicator of blood stasis, and sequestration was evaluated by the platelets/RBC and PMN/RBC ratios.

Samples from the cerebral cortex were fixed by immersion in glutaraldehyde $5 \%$ in $0.1 \mathrm{M}$ cacodylate buffer and embedded in epon. Micrographs were randomly taken from capillaries at 10,000-fold magnification. Twenty pictures were obtained from two blocks from each individual mouse. To evaluate the endothelial surface and volume, the pictures were overlaid with a lattice of bar and points (Weibel, 1990) and intersection with the endothelial surface, and the basement membrane and points within the endothelium were counted. The endothelial surface (SE) was estimated as a ratio between intersections with the endothelial surface and the basement membrane. Endothelial volume ( $\mathrm{Ve}$ ) was estimated as the ration of the points within the endothelium to the intersections with the basement membrane. Venules were also examined in the same preparations.

\section{Immunohistochemistry}

Frozen tissue sections were immunostained as described elsewhere. Briefly, $5 \mu \mathrm{m}$ sections were incubated overnight at room temperature with a rat monoclonal antibody antibodies: anti-CD54 and anti-CD106 monoclonal antibody as described previously (Favre et al, 1999) or anti-CD40 monoclonal antibody FGK45 (Rolink et al, 1996). After washing, sections were incubated 1 hour with FITC-labeled goat anti-rat immunoglobulin (Southern Biotechnology, Bioreba, Reinach, Switzerland).

\section{Evaluation of TNF Serum Level}

TNF serum level was assayed by using the DuoSet Elisa (RD systems, Minneapolis, Minnesota), which detects both free and receptor bound TNF with a sensitivity of $12 \mathrm{pg} / \mathrm{ml}$.

\section{Evaluation of TNF, CD40L, and CD54 and CD40 mRNAs Levels}

TNF- $\alpha$ (Piguet et al, 1989), CD40L (Mendoza et al, 1997), and CD54 (Horley et al, 1989) mRNAs levels were evaluated on Northern blots using ${ }^{32} \mathrm{P}$-labeled dUTP riboprobes. Quantification of mRNAs was per- formed using the Phosphorlmager analysis (Molecular Dynamics, Inc., Sunnyvale, California) and the amount, measured in arbitrary units, was normalized to the 18S RNA (Barazzone et al, 1998).

\section{Statistical Evaluation}

Significance analysis of survival curves was determined by the Fisher exact test. Groups of values were compared using the nonparametric Mann and Whitney test (Mann and Whitney, 1947).

\section{References}

Abe A, Sekiya S, Yamasita T, and Senso F (1990). Vascular hyperpermeability induced by tumor necrosis factor and its augmentation by IL-1 and IFN-gamma is inhibited by selective depletion of neutrophils with monoclonal antibody. J Immunol 145:2902-2907.

Ault KA and Knowles C (1995). In vivo biotinylation demonstrates that reticulated platelets are the youngest platelets in circulation. Exp Hematol 23:996-1001.

Baker SJ and Reddy EP (1998). Modulation of life and death by the TNF receptor superfamily. Oncogene 17:3261-3270.

Barazzone C, Horowitz S, Donati Y, Vesin C, Rochat A, Rodriguez I, and Piguet PF (1998). Oxygen toxicity in mouse lung: Pathways to cell death. Am J Respir Cell Mol Biol 19:573-581.

Carvalho LJM, Lenzi HL, Pelajo-Machado M, Oliveira DN, and Daniel-Ribeiro CT (2000). Plasmodium berghei: Cerebral malaria in CBA mice is not clearly related to plasma TNF levels or intensity of histopathological changes. Exp Parasitol 95:1-7.

Chang-Ling T, Neill AL, and Hūnt NH (1992). Early microvascular changes in murine cerebral malaria detected in retinal wholemounts. Am J Pathol 140:1121-1130.

Clark IA, Al Yaman FM, and Jacobson LS (1997). The biological basis of malarial disease. Int J Parasitol 27:12371249.

Clark IA and Bowden WB (1992). Role of TNF in malaria and other parasitic infections. In: Aggarwal BB and Vilcek J, editors. Tumor necrosis factor: Structure, function and mechanism of action. New York: Dekker, 365-4007.

Clark IA, Macmicking JD, Gray KM, Rockett KA, and Cowden WB (1992). Malaria mimicry with tumor necrosis factor. Contrasts between species of murine malaria and plasmodium falciparum. Am J Pathol 140:325-336.

Coquelin F, Boulard Y, Mora-Silvera E, Richard F, Chabaud AG, and Landau I (1999). Final stage maturation of the erythrocytic schizonts of rodent Plasmodium in the lungs. C R Acad Sci III 322:55-62.

Cotran RS, Kumar V, Robbins SL, and Schoen FS (1994). The pancreas. In: The pathologic basis of disease. Philadelphia: WB Saunders, 897-926.

Curfs JHAJ, Schetters TPM, Hermsen CC, Jerusalem CR, Van Zon AAJC, and Eling WMC (1989). Immunological aspects of cerebral lesions in murine malaria. Clin Exp Immunol 75:136-143.

Douni E and Kollias G (1998). A critical role of the p75 tumor necrosis factor receptor (p75TNF-R) in organ inflammation 
independent of TNFR, Lymphotoxin-alpha or the p55TNF-R. J Exp Med 188:1343-1352.

Elased KM, Taverne J, and Playfair JH (1996). Malaria, blood glucose, and the role of tumour necrosis factor (TNF) in mice. Clin Exp Immunol 105:443-449.

Engwerda CR, Mynott TL, Sawhney S, de Souza JB, Bickle QD, and Kaye PM (2002). Locally up-regulated lymphotoxin alpha, not systemic tumor necrosis factor alpha, is the principle mediator of murine cerebral malaria. J Exp Med 195:1371-1377.

Evans RD, Argiles JM, and Williamson DH (1989). Metabolic effects of tumour necrosis factor-alpha (Cachectin) and interleukin-1. Clin Sci 77:357-364.

Favre N, Willimann K, Ryffel B, Weiss N, Imhof BA, Rudin W, Lucas R, and Piguet PF (1999). Role of ICAM-1 in the development of murine cerebral malaria. Microbes Infection 1:961-968.

Feng D, Nagy JA, Pyne K, Hammel I, Dvorak HF, and Dvorak AM (1999). Pathways of macromolecular extravasation across microvascular endothelium in response to VPF/VEGF and other vasoactive mediators. Microcirculation 6:23-44.

Grau GE, Fajardo LF, Piguet PF, Allet B, Lambert PH, and Vassalli P (1987). Tumor necrosis factor (cachectin) as an essential mediator in murine cerebral malaria. Science 237 : 1210-1212.

Grau GE, Heremans H, Piguet PF, Pointaire P, Lambert PH, Billiau A, and Vassalli $P$ (1989). Monoclonal antibody against interferon-gamma can prevent experimental cerebral malaria and its associated overproduction of tumor necrosis factor. Proc Natl Acad Sci USA 86:5572-5574.

Grau GE, Piguet PF, Gretener D, Vesin C, and Lambert PH (1988). Immunopathology of thrombocytopenia in experimental malaria. Immunology 65:501-506.

Grau GE, Pointaire P, Piguet PF, Vesin C, Rosen H, Stamenkovic I, Takei F, and Vassalli P (1991). Late administration of monoclonal antibody to leukocyte function antigen 1 abrogates incipient murine cerebral malaria. Eur $\mathrm{J}$ Immunol 21: 2265-2267.

Grau GE, Tacchini-Cottier F, Vesin C, Milon G, Lou JN, Piguet PF, and Julliard P (1993). TNF-induced microvascular pathology: Active role for platelets and importance of the LFA-1/ICAM-1 interaction. Eur Cytokine Netw 4:415-419.

Holloway PA, Krishna S, and White NJ (1991). Plasmodium berghei: Lactic acidosis and hypoglycemia in a rodent model of severe malaria: Effects of glucose, quinine, dichloroacetate. Exp Parasitol 72:123-133.

Horley KJ, Carpeinto C, Baker B, and Takei F (1989). Molecular cloning of murine intercellular adhesion molecule (ICAM1). EMBO J 8:2889.

Imhof BA and Dunon D (1995). Leukocyte migration and adhesion. Adv Immunol 58:345-416.

Kwiatkowski D (2000). Genetic susceptibility to malaria getting complex. Curr Opin Genet Dev 10:320-324.

Kwiatkowski D, Hill AVS, Sambou I, Twumasi P, Castracane J, Manogue KR, Cerami A, Brewster DR, and Greenwood BM (1990). TNF concentration in fatal cerebral, non-fatal cerebral, and uncomplicated plasmodium falciparum malaria. Lancet 336:1201-1204.

Liu LS, Spelleken M, Röhrig K, Hauner H, and Eckel J (1998). Tumor necrosis factor-alpha acutely inhibits insulin signaling in human adipocytes. Implication of the p80 tumor necrosis factor receptor. Diabetes 47:515-522.

Lucas R, Juillard P, Decoster E, Redard M, Burger D, Donati Y, Giroud C, Monso Hinard C, De Kesel T, Buurman WA, Moore MW, Dayer JM, Fiers W, Bluethmann H, and Grau GE (1997a). Crucial role of tumor necrosis factor (TNF) receptor 2 and membrane-bound TNF in experimental cerebral malaria. Eur J Immunol 27:1719-1725.

Lucas R, Lou JN, Juillard P, Moore M, Bluethmann H, and Grau GE (1997b). Respective role of TNF receptors in the development of experimental cerebral malaria. J Neuroimmunol 72:143-148.

Mann HB and Whitney DR (1947). On a test of whether one or two random variables is stochastically larger than the other. Ann Math Stat 18:50-60.

Marsh K, English M, and Crawley J (1996). The pathogenesis of severe malaria in African children. Ann Trop Med Parasitol 90:395-402.

Mendoza RB, Cantwell MJ, and Kipps TJ (1997). Immunostimulatory effects of a plasmid expressing CD40 ligand (CD154) on gene immunization. J Immunol 159:5777-5781.

Newton CRJC, Peshu N, Kendall B, Kirkham FJ, Sowunmi A, Waruiru C, Mwangi I, Murphy SA, and Marsh K (1994). Brain swelling and ischemia in kenyans with cerebral malaria. Arch Dis Child 70:281-287.

Omer FM and Riley EM (1998). Transforming growth factor beta production is inversely correlated with severity of murine malaria infection. J Exp Med 188:39-48.

Piguet PF, Collart MA, Grau GE, Kapanci Y, and Vassalli P (1989). Tumor necrosis factor/cachectin plays a key role in bleomycin-induced pneumopathy and fibrosis. J Exp Med 170:655-663.

Piguet PF, Kan CD, and Vesin C (2002). Thrombocytopenia in an animal model of malaria is associated with an increased caspase-mediated death of thrombocytes. Apoptosis 7:9198.

Piguet PF, Kan CD, Vesin C, Rochat A, Donati Y, and Barazzone C (2001a). Role of CD40-CD40L in mouse severe malaria. Am J Pathol 159:733-742.

Piguet PF, Laperousaz CD, Vesin C, Tacchini-Cottier F, Senaldi G, and Grau GE (2000a). Delayed mortality and attenuated thrombocytopenia associated with severe malaria in urokinase and urokinase-receptor (UPAR, CD87) deficient mice. Infect Immun 68:3822-3829.

Piguet PF, Vesin C, Laperousaz CD, and Rochat A (2000b). Role of plasminogen activators and of urokinase receptor (UPAR, CD87) in platelet kinetics in mice. Hematology $\mathrm{J}$ 1:199-205.

Piguet PF, Vesin C, and Rochat A (2001b). Beta-2 integrin modulates platelet caspase activation and life span in mice. Eur J Cell Biol 80:171-177.

Pober JS (2002). Endothelial activation: Intracellular signaling pathways. Arthritis Res 4:S109-S116.

Polder TW, Eling WMC, Curfs JHAJ, Jerusalem CR, and Wijers-Rouw M (1992). Ultrastructural changes in the bloodbrain barrier of mice infected with the Plasmodium berghei. Acta Leiden 60:31-46.

Rolink A, Melchers F, and Andersson J (1996). The Scid but not the Rag-2 gene product is required for $S$ mu-S epsilon heavy chain class switching. Immunity 5:319-330. 
Rudin W, Eugster HP, Bordmann G, Bonato J, Muller M, Yamage M, and Ryffel B (1997). Resistance to cerebral malaria in tumor necrosis factor-alpha/beta-deficient mice is associated with a reduction of intercellular adhesion molecule-1 up-regulation and T helper type 1 response. Am J Pathol 150:257-266.

Saltiel AR and Kahn CR (2002). Insulin signaling and the regulation of glucose and lipid metabolism. Nature 414:799806.

Senaldi G, Vesin C, Chang R, Grau G, and Piguet PF (1994). An effector role of neutrophils in the pathogenesis of murine severe malaria. Infect Immun 62:1144-1149.

Sethi JK, Xu H, Uysal KT, Wiesbrock SM, Scheja L, and Hotamisligil GS (2000). Characterization of receptor-specific TNF-alpha functions in adipocyte cell lines lacking type-1 and 2 TNF receptors. FEBS Lett 469:77-82.

Stewart PA, Hayakawa K, and Farrell CL (1994). Quantitation of blood-brain barrier ultrastructure. Micro Res Tech 27:516527.

Tacchini-Cottier F, Vesin C, Redard M, Buurman W, and Piguet PF (1998). Role of TNF receptors I and II in TNFinduced platelets consumption in mice. J Immunol 160: 6182-6186.

Thumwood CM, Hunt NH, Clark IA, and Cowden WB (1988). Breakdown of the blood-brain barrier in murine cerebral malaria. Parasitology 96:579-589.
Tracey KJ, Beutler B, Lowry SF, Merryweather J, Wolpe S, Milsark IW, Hariri RJ, Fahey TJ, Zentella A, Albert JD, Shires GT, and Cerami A (1986). Shock and tissue injury induced by recombinant human cachectin. Science 234:470-474.

Uysal KT, Wiesbrook SM, and Hotamisligil GS (1998). Functional analysis of tumor necrosis factor (TNF) receptor in TNF-alpha-mediated insulin resistance in genetic obesity. Endocrinology 139:4832-4838.

Van Thien H, Ackermans MT, Dekker E, Thanh Chien VO, Le T, Endert E, Kager PA, Romijn JA, and Sauerwein HP (2001). Glucose production and gluconeogenesis in adult with cerebral malaria. QJM 94:709-715.

Weibel ER (1990). Morphometry: Stereological theory and practical methods. In: Gil J, editor. Models of lung disease, microscopy and structural methods. New York: Dekker, 199-252.

White NJ and Ho M (1992). The pathophysiology of malaria. In: Advances in parasitology. New York: Academic Press, 84-173.

Wright DH (1968). The effect of neonatal thymectomy on the survival of golden hamsters infected with Plasmodium berghei. Br J Exp Pathol 49:379-384.
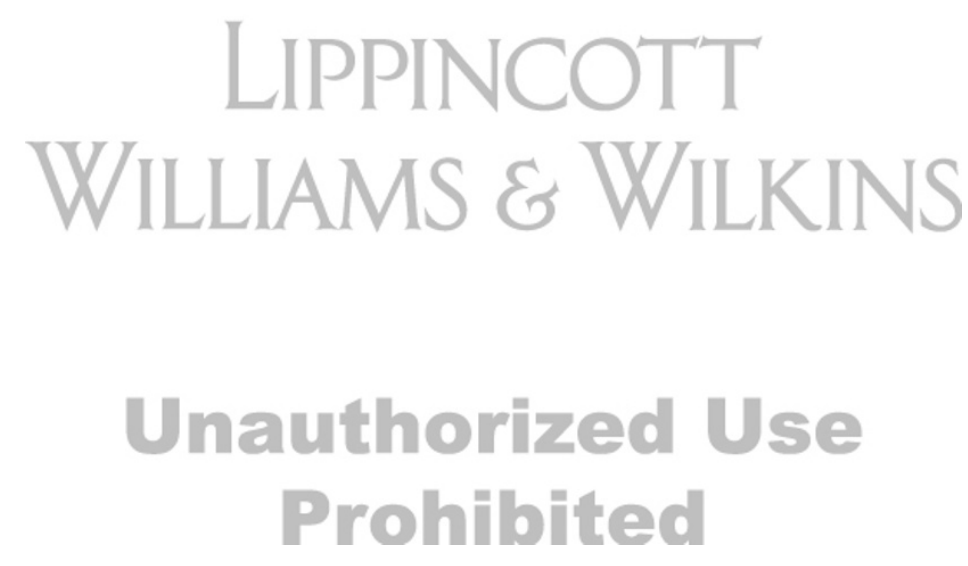